\title{
PROSES CONTROL SYSTEM PADA MESIN STAMPING BERBASIS INTERNET OF THING
}

\author{
Suharyadi Pancono ${ }^{1}$, Gun Gun Maulana ${ }^{2}$, Vera $S^{3}$ \\ ${ }^{1}$ Politeknik Manufaktur Bandung \\ Jl. Kanyakan no 21 Bandung \\ 2 Politeknik Manufaktur Bandung \\ Jl. Kanyakan no 21 Bandung \\ ${ }^{3}$ Ttelkom Universiy \\ Jl. Terusan Buah Batu No 205 Bandung \\ ${ }^{1}$ suharyadi_p@polman-bandung.ac.id, ${ }^{2}$ gungun@polman-bandung.ac.id, ${ }^{3}$ vera_s@telu.ac.id
}

Abstrak - Di era modern seperti sekarang ini kompetisi didunia bisnis hampir terjadi disemua bidang, tak terkecuali pada bidang manufaktur dimana mereka harus beradaptasi dengan teknologi agar produksi tetap bisa bertahan, salah satu alat produksi pada bidang manufaktur adalah mesin stamping dimana mesin stamping merupakan mesin bertenaga pneumatik, hidrolik atau mekanik yang digunakan untuk menekan sebuah benda dan menghasilkan benda baru dengan volume yang lebih padat. Dalam dunia industri perusahaan membutuhkan sebuah sistem kontrol yang handal untuk merealisasikan otomasi industri dengan tingkat efisiensi yang tinggi, sehingga kegiatan perawatan dan pemantauan mesin tidak membutuhkan biaya yang mahal dan rumit karena informasi dapat diterima dengan cepat dan mudah. Process Control System Berbasis Internet of Thing adalah alat pengontrol produksi yang digunakan untuk membantu pihak management dan operator dalam mendapatkan informasi tentang kondisi suatu mesin di plant dan memvisualisasikannya. Alat kontrol tersebut sangat penting dalam membantu industri untuk mencapai tujuan produksi yang diinginkan, mengurangi waktu yang terbuang dan meningkatkan hasil produksi. Adapun hasil yang diharapkan adalah sebuah Process Control System pada Mesin Stamping Berbasis Internet of Thing agar informasi dapat ditampilkan melalui grafik secara realtime dan reliable; serta data yang tersimpan di dalam database dan dapat diakses secara berkala, baik per minggu, per bulan, ataupun per tahun. Serta informasi dapat di akses kapanpun dan dimanapun melalui perangkat smartphone berbasis android sehingga proses kontrol produksi menjadi lebih efektif dan efisien.

Kata Kunci_ Process Control System, Android, Stamping Machine, Internet of Things

Abstract - Abstract - In this modern era, competition in the business world occurs in almost all fields, including in manufacturing, where they have to adapt to technology so that production can survive, one of the production tools in manufacturing is a stamping machine where the stamping machine is a pneumatic powered machine., hydraulics or mechanics used to press an object and produce a new object with a denser volume. In the industrial world, companies need a reliable control system to realize industrial automation with a high level of efficiency, so that maintenance and machine monitoring activities do not require expensive and complicated costs because information can be received quickly and easily. Process Control System based on the Internet of Thing is a production control tool used to assist management and operators in obtaining information about the condition of a machine in a plant and visualizing it. These controls are essential in helping the industry to achieve its desired production goals, reduce wasted time and increase production yields. The expected results are a Process Control System on an Internet of Thing-based Stamping Machine so that information can be displayed via graphs in realtime and reliably; as well as data that is stored in the database and can be accessed regularly, either per week, per month, or per year. And information can be accessed anytime and anywhere via an Android-based smartphone so that the production control process becomes more effective and efficient.

Keywords - Process Control System, Android, Stamping Machine, Internet of Things

\section{PENDAHULUAN}

Di era modern seperti sekarang ini kompetisi didunia bisnis hampir terjadi disemua bidang, tak terkecuali pada bidang manufaktur dimana mereka harus beradaptasi dengan teknologi agar produksi masih tetap bisa bertahan, salah satunya pada mesin press. Mesin Press adalah mesin bertenaga pneumatik, hidrolik atau mekanik yang digunakan untuk menekan sebuah benda dan menghasilkan benda baru dengan volume yang lebih padat [1]. Dalam dunia industri sebuah perusahaan membutuhkan sebuah sistem 
monitoring produksi yang handal. Process Control System adalah hal yang sangat penting untuk merealisasikan otomasi industri dengan tingkat efisiensi yang tinggi [2] sehingga kegiatan perawatan dan pemantauan tidak membutuhkan biaya mahal dan rumit untuk mendapatkan data yang dapat diandalkan setiap waktu [3]. Situasi ini memotivasi para peneliti untuk membuat cara-cara inovatif pemantauan produksi dan pemeliharaan kinerja pada kondisi peralatan [4]. Pemantauan merupakan bagian penting dari informasi sistem yang digunakan dalam industri untuk meningkatkan efektivitas dan meminimalkan downtime yang tidak direncanakan [5]. Umumnya informasi yang perlu dipantau diindustri adalah tipe part yang dibuat, jumlah part yang telah diproduksi, Gross Stroke Per hour, life-time part, dan life time mesin [6] dari informasi yang didapat dapat dilakukan perhitungan untuk mengetahui Availibility, performance, Quality, dan Overall Equipment Effectiveness [17]. Saat ini proses monitoring di industri masih dilakukan secara manual dimana informasi didapatkan dari operator yang mengecek dan mengupdate kondisi terbaru pada mesin [7]. Informasi yang diperoleh secara manual tentu tidak reliable karena sering terjadi kesalahan pada operator, yang tentu bisa berdampak pada sistem produksi dan dan bisa merugikan perusahaan, selain itu sistem monitoring secara manual tidak efektif dan tidak efisien karena membutuhkan waktu yang cukup lama untuk mengupdate informasi [7]. Data produksi yang dikumpulkan pada saat ini masih banyak kesalahan karena intervensi manusia atau sistem pemantauan produksi yang tidak semestinya. Faktor manusia lebih banyak terjadi pada kasus ini. Seperti saat pemadaman unschedule terjadi, maka waktu dihabiskan untuk memecahkan masalah tersebut, sehingga hal ini dapat mengganggu proses produksi di perusahaan [8].

Process Control System berbasis Internet of Thing adalah alat produksi yang digunakan membantu management untuk mendapatkan dan menyebarkan informasi tentang keadaan pada suatu mesin di plant dan memvisualisasikannya [20]. Process Control System sangat penting dalam membantu industri untuk mencapai tujuan produksi yang diinginkan, mengurangi waktu yang terbuang dan meningkatkan hasil produksi [10]. Process Control System harus memberikan informasi yang tepat, efektif dan efisien [11]. Process Control System dibuat agar dapat memberi informasi yang penting baik bagi manager, supervisor, teknisi, maupun operator dan dapat menentukan solusi dari permasalahan yang terjadi dengan cepat [11]. Process Control System berbasis Internet Of Thing yang dirancang untuk mesin press memungkinkan perolehan data dari Mesin Press berkaitan dengan Jumlah dan Tipe part yang dibuat, $G S P H$, vibration, air pressure, life time, tipe part, Mean to repair, dan jumlah actual production mesin yang dihubungkan dengan Internet dengan menggunakan cloud realtime database pada firebase sebagai penyimpanan data[12] dan diolah pada Android sebagai user interface [13] merupakan dari data yang diterima sehingga dapat diakses pada LED TV, smartphone, personal comuter, Laptop yang terhubung dengan internet membuat user dapat mengakses dimana saja dan kapan saja sehingga permasalahan dan kondisi mesin dapat dipantau secara realtime dan data yang diterima akan disimpan di Android sebagai hasil produksi mesin press[14]. Hal ini dilakukan agar dapat meningkatkan kapasitas produksi, efisiensi biaya, dan membantu mencapai target produksi yang diinginkan [15]. Dengan adanya sistem tersebut kesalahan dapat terdeteksi sedini mungkin sehingga akan mengurangi waktu yang terbuang dan meningkatkan performance mesin secara keseluruhan dan mengurangi resiko kritis mesin [16]. Sehingga dengan Process Control System berbasis Internet of Thing pada mesin press ini diharapkan sistem produksi akan menjadi lebih efektif dan efisien. 


\section{METODE PENELITIAN}

\section{A. Gambaran Umum}

Page | 50

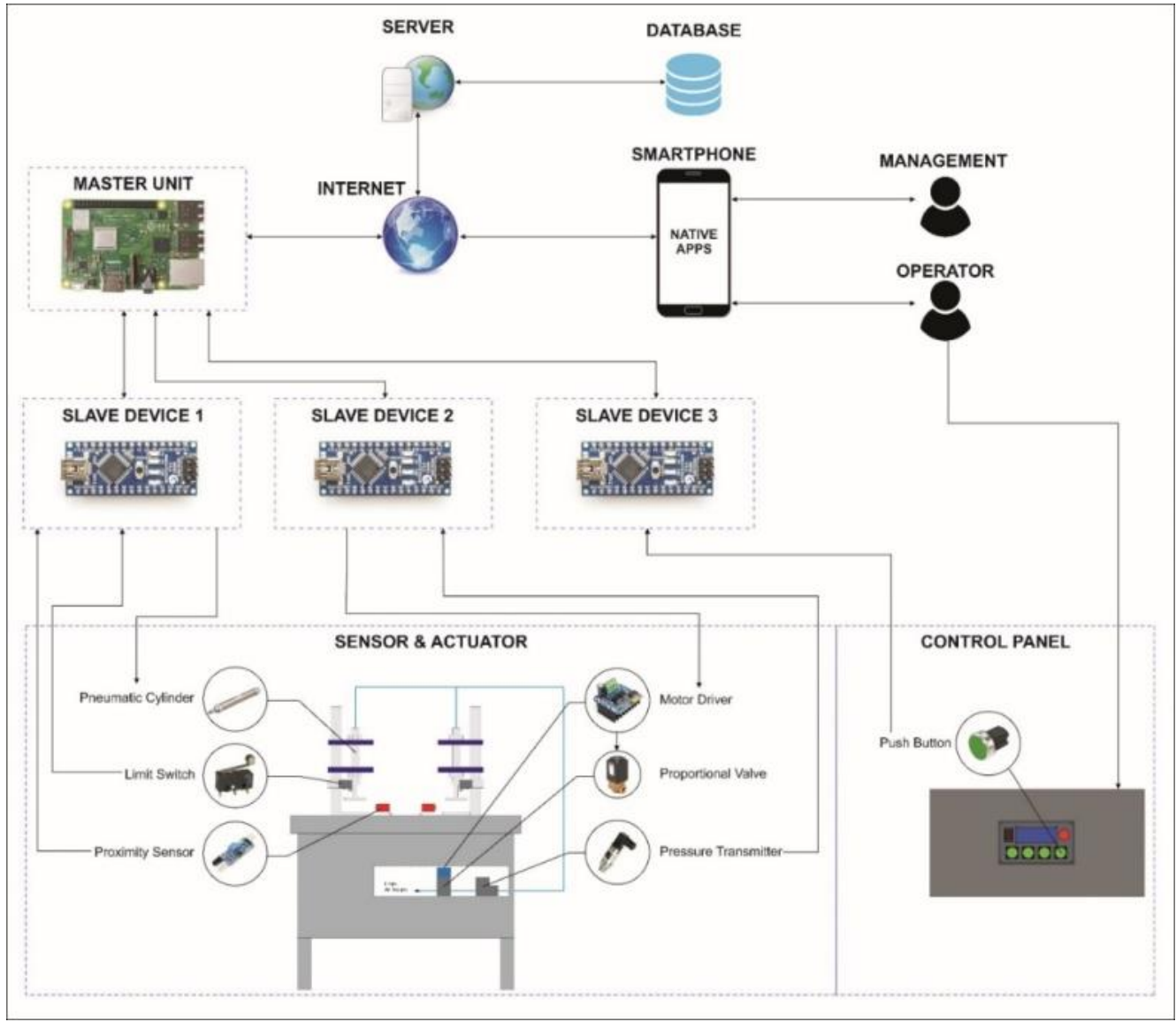

Gbr 1. Gambaran Umum Sistem

Pada gambar 1. diatas menunjukkan Sebuah informasi tentang kondisi Mesin Stamping yang dapat diakses via smartphone berbasis android, dimana mesin stamping yang digunakan berupa silinder pneumatic bertenaga angin yang digunakan sebagai tenaga utama dari mesin tersebut. Untuk mengontrol sumber angin agar tekanan yang diberikan stabil diperlukan sebuah valve yang dapat mengatur keluaran angin yang didistribusikan ke silinder pneumatik. Selain itu juga, agar tekanan angin dapat terpantau diperlukan sebuah sensor/transmitter yang dapat mengukur nilai tekanan angin dan dapat menjadi feedback untuk valve agar tekanan dapat dikontrol sesuai dengan nilai yang diinginkan.

Kemudian, pada umumnya informasi yang perlu dipantau di industri dari sebuah proses produksi adalah tipe part yang dibuat, jumlah part yang telah diproduksi, life-time part, dan life time mesin dari informasi yang didapat dapat dilakukan perhitungan untuk mengetahui Availability, Performance, Quality, dan Overall Equipment Effectiveness (OEE). Oleh karena itu, diperlukan sensor untuk mendeteksi jumlah produksi dari setiap mesin press agar perhitungan dapat dilakukan secara otomatis.

Untuk mengintegrasikan Process Control System ini melalui Internet of Things, data disimpan di database cloud secara online dan realtime sehingga semua informasi dapat diakses dan ditampilkan pada user-interface. Untuk mengatasi masalah pada userinterface dari penelitian sebelumnya, maka pada penelitian ini aplikasi user-interface perlu dibuat suatu teknologi yang dapat menjawab masalah-masalah tersebut.

\section{B. Alur tahapan Penelitian}

1) Studi literature : Pada tahapan ini dilakukan pengumpulan materi-materi dari berbagai sumber yang berhubungan dengan sistem yang akan dibuat. Materimateri tersebut dipelajari dan dijadikan sebagai acuan dasar pembuatan sistem.

2) Perancangan dan pemodelan system : Perancangan sistem prototipe Process Control System mesin press meliputi perancangan mekanik, perancangan elektrik, dan juga perancangan serta pemodelan algoritma pemrograman. Tahap ini dimaksudkan agar memudahkan dalam pelaksanaan 
penelitian, dan juga mengurangi tingkat kesalahan saat melaksanakan penelitian.

3) Pengerjaan mekanik system : Setelah perancangan selesai kemudian pembuatan mekanik untuk prototype mesin press. Tahap ini meliputi

Page 51 penyediaan bahan-bahan dan komponen-komponen yang akan digunakan dalam penelitian. Kemudian, bahan-bahan dan komponen-komponen tersebut dibangun menjadi mekanik prototipe Process Control System mesin press.

4) Pengerjaan rangkaian pneumatic : Setelah menyelesaikan pengerjaan mekanik untuk prototipe mesin. Tahapan ini meliputi penyediaan bahan-bahan dan komponen yang akan digunakan dalam penelitian. Selanjutnya bahan dan komponen tersebut akan di rangkai sesuai gambar rangkaian pneumatic yang sudah dibuat.

5) Pengerjaan rangkaian elektrik system : Setelah pembuatan mekanik sistem pelayangan magnetik selesai, selanjutnya adalah perangkaian rangkaian listrik dari sistem pelayangan magnetik sesuai dengan gambar rangkaian listrik yang sudah dibuat pada tahap perancangan sistem pelayangan magnetik.

6) Pembuatan program pengendali : Pada tahap ini dilakukan pemrograman pengendali prototipe bendung. Pemrograman dilakukan sesuai dengan algoritma yang sudah dirancang pada tahap perancangan sistem prototipe bendung. Setelah program selesai dibuat, dilakukan uji coba program tersebut sekaligus menganalisanya. Apabila berhasil maka lanjut ke tahap pembuatan program antarmuka untuk pemantauan sistem prototipe bendung, apabila tidak maka kembali lagi ke tahap pembuatan program pengendali.

7) Pembuatan program antarmuka : Pada tahap ini dilakukan pemrograman antarmuka untuk pemantauan sistem kendali prototipe Process Control System mesin press. Pemrograman dilakukan sesuai dengan algoritma yang sudah dirancang pada tahap perancangan Setelah program selesai dibuat, dilakukan uji coba program tersebut sekaligus menganalisa nya. Apabila berhasil maka lanjut ke tahap integrasi dan pengujian sistem secara keseluruhan, apabila tidak maka kembali lagi ke tahap pembuatan program pengendali.

8) Integrasi dan pengujian system : Pada tahapan ini dilakukan penggabungan sistem secara keseluruhan, baik sistem mekanik, elektrik, dan juga program kendali serta antarmuka menjadi sebuah prototipe. Kemudian dilakukan pengujian sistem yang sudah dirakit menjadi sebuah prototipe. Hasil yang diharapkan dari pengujian ini GSPH, life time, tipe part, mean to repair dan jumlah actual production mesin press dapat dipantau secara real time tanpa dimana saja, sehingga data dapat digunakan oleh management untuk preventive mesin atau dapat memberikan keputusan secara cepat apabila terjadi suatu masalah dapat dipantau menggunakan handphone, LED TV, Laptop, Smartphone yang terhubung ke internet.

9) Analisis : Pada tahapan ini hasil dari pengujian sistem akan di analisis dan disimpulkan, kemudian disusun menjadi sebuah laporan yang sistematis.

\section{Perancangan Domain Spesifik}

Perancangan domain spesifik ini merupakan penguraian dari perancangan sistem secara spesifik dari setiap domainnya

1) Perancangan Domain Mekanik : Sistem mekanik yang akan diterapkan pada sistem ini dirancang untuk menunjang setiap perangkat keras yang akan digunakan pada mesin press. Secara garis besar sistem mekanik ini tersusun dari material aluminium profil, plat aluminium, dan akrilik. Selain itu sistem mekanik pada mesin press ini dibagi menjadi dua, yaitu bagian atas dan bagian bawah.

2) Perancangan Domain Elektrik : Pada perancangan domain elektrik ini dijabarkan mengenai sistem elektrik prototipe mesin press. Perancangan sistem elektrik ini meliputi perancangan rangkaian source power, master unit, slave device, relay to solenoid valve, dan indikator lampu, dan rangkaian pneumatik silinder. Perancangan sistem elektrik ini dirancang sedemikian rupa sehingga dapat menyokong fungsi dari Process Control System pada prototipe mesin press yang efektif.

3)Perancangan Domain Informatik: Pada perancangan domain informatik ini dijabarkan mengenai sistem informatika pada Process Control System. Perancangan sistem informatik ini meliputi diagram alir proses stamping, diagram alir proses pengiriman dan penerimaan data antara database dengan user interface, diagram alir proses pengiriman data antara database dengan mesin, rancangan database, rancangan tampilan user-interface, dan rancangan program kontrol. Untuk mengetahui alur dari sistem monitoring ini maka diperlukan rancangan flowchart proses operasi Process Control System. Flowchart ini diperlukan selain untuk memberikan gambaran alur kerja dari production monitoring sistem, flowchart ini juga dapat mempermudah proses program kontrol, program Android service, dan program User-Interface.

1. Proses Kerja Mesin dan Sistem Informasi. Berikut adalah tampilan flowchart Process Control System pada prototipe mesin press berbasis aplikasi mobile. 


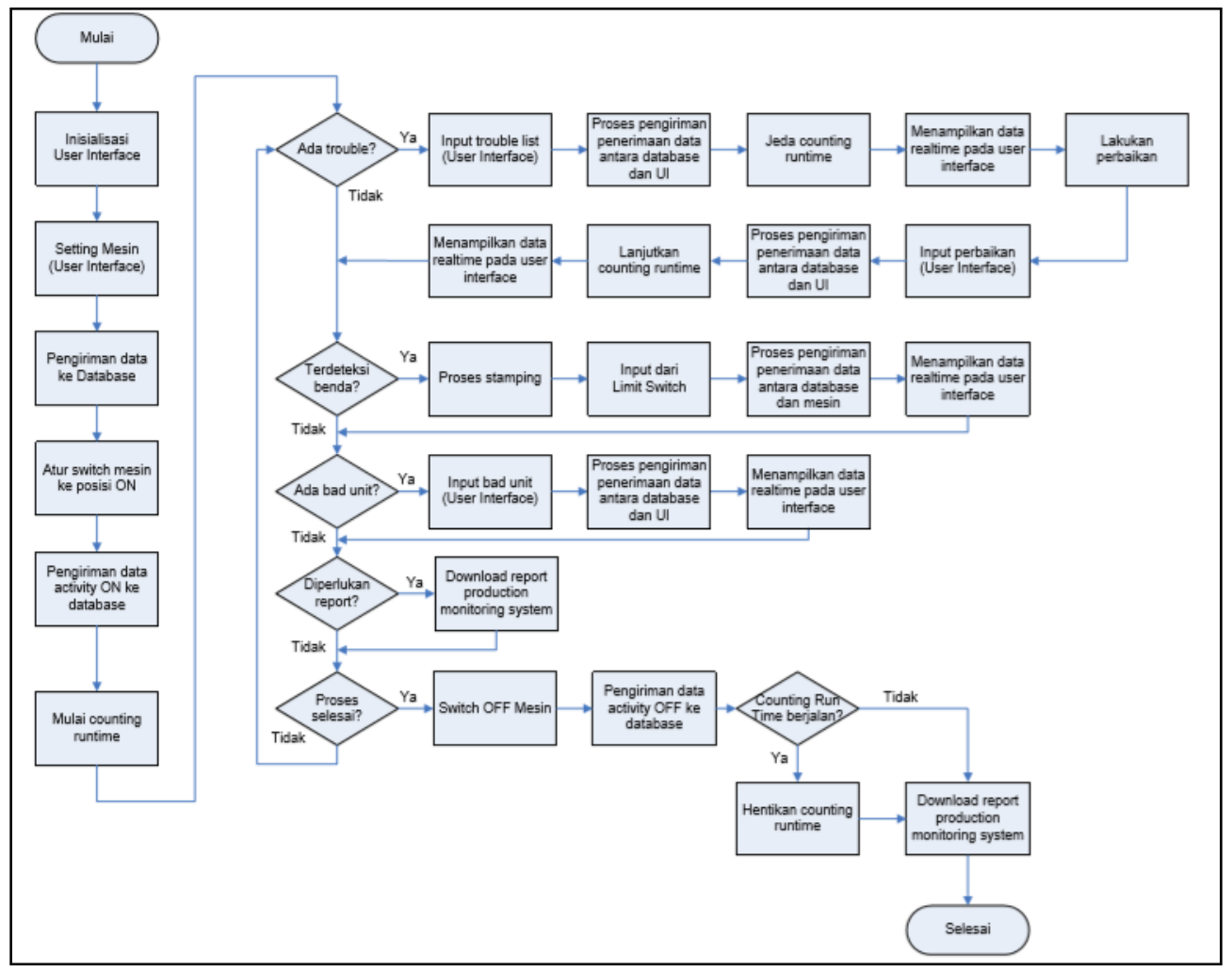

Gbr 2. Flowchart Proses Stamping - Report

Pada gambar 2 ditunjukkan tahapan proses Process Control System pada penelitian ini mulai dari pengaturan parameter mesin hingga menghasilkan report. Proses pertama adalah inisialisasi User Interface pada proses ini user membuka aplikasi User Interface dan melakukan login. Kemudian proses berikutnya adalah proses setting mesin. Pada proses ini terdapat beberapa parameter yang perlu dimasukkan diantaranya adalah waktu produksi, tipe produk, dan cycle time. Setelah parameter sudah ditentukan maka proses berikutnya adalah pengiriman data dari UserInterface ke Database. Setelah itu, proses berikutnya adalah pengaturan switch on pada mesin untuk memulai proses stamping. Setelah posisi switch dalam keadaan ON, proses berikutnya adalah pengiriman data activity ON ke database kemudian menjadi penanda proses stamping sudah dimulai. Selain itu juga disaat yang bersamaan proses berikutnya adalah memulai counting timer runtime/operation time. Setelah proses tersebut, melakukan proses looping proses decision jika tidak ada error, tidak terdeteksi benda, tidak ada bad product, tidak diperlukan report, atau proses belum selesai sampai terdapat decision ya. Jika ada error pada mesin input trouble list oleh operator. Proses berikutnya adalah pengiriman dan penerimaan data antara user interface dan database. Setelah operator memasukkan trouble list, maka proses berikutnya adalah counting timer runtime akan dijeda.
Setelah itu, parameter baru mesin akan ditampilkan pada interface. Proses berikutnya adalah lakukan perbaikan. Jika sudah dilakukan perbaikan maka engineer memasukkan repairment list dan akan dikirimkan ke database. Setelah itu proses counting runtime kembali berjalan. Setelah itu juga data terbaru akan ditampilkan di User-Interface. Jika terdeteksi benda oleh sensor Infrared maka proses berikutnya adalah proses stamping. Ketika proses stamping silinder akan melakukan trigger ke limit switch. Setelah itu proses pengiriman data ke database untuk counting up produk. Setelah data ter update maka, User-Interface akan menampilkan data terbaru. Kemudian jika ada bad unit, maka input bad unit oleh operator. Kemudian data akan dikirim ke database dan setelah data ter update maka tampilan User-Interface akan menampilkan data terbaru. Kemudian, jika diperlukan report sementara maka lakukan proses download report. Kemudian jika proses sudah selesai maka atur Posisi switch ke posisi OFF. Setelah itu proses report akhir mesin dapat diunduh.

Dari alur yang ditunjukkan gambar III-14 terdapat proses pengiriman dan penerimaan data antara database dan User Interface, serta pengiriman data dari mesin ke database.

\section{Perancangan Database}

Berikut adalah skema relasi rancangan database Process Control System. 


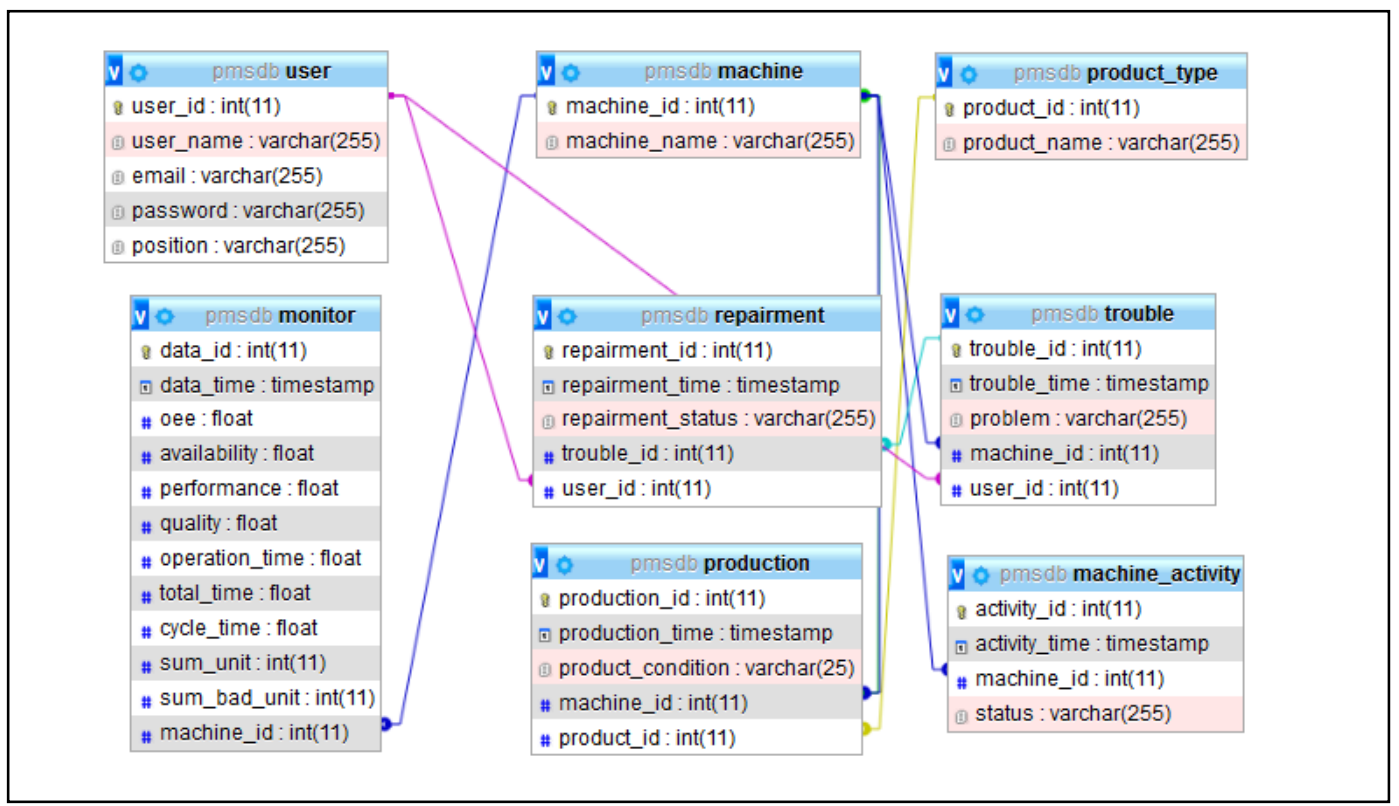

Gbr 3. Skema Relasi Database

Terdapat beberapa table seperti yang ditunjukkan pada gambar 3. Terdapat 8 tabel yang dirancang pada Process Control System ini. Tabel-tabel tersebut dapat dibagi menjadi table master dan table transaksi. Tabel master meliputi table user, machine, dan product type. Sementara table transaksi meliputi table monitor, repairmen, trouble, production, dan machine activity.

\section{HASIL DAN PEMBAHASAN}

Pada bab ini dipaparkan mengenai hasil penelitian yang sudah dilakukan yang meliputi pengujian sensor dan tombol, pengujian antarmuka, dan pengujian repeatability sistem.

\section{A. Tampilan User Interface}

Selain itu juga rancangan berikutnya adalah perancangan tampilan User-Interface. User Interface ini termasuk ke dalam modul visualisasi dari Process Control System. Proses pengembangan User Interface terkait erat dengan data, yang dikumpulkan dalam lokakarya. Salah satu ide visualisasi adalah menyajikan data yang kompleks dengan cara yang sederhana dan mungkin membantu menemukan pola dalam sejumlah besar data dan mengambil keputusan cepat. Adapun beberapa elemen yang terdapat dalam visualisasi modul berdasarkan konsep sederhana dari sebuah Process Control System, yaitu sistem alarm, reports, working data. Oleh karena itu, untuk memenuhi konsep sederhana sebuah Process Control System tersebut maka pada tampilan User Interface diperlukan elemen-elemen tersebut yang dibagi di dalam beberapa screen User Interface. Selain itu juga, pada user interface terdapat tingkatan user yang berbeda dimana setiap tingkatan user tersebut memiliki beberapa tampilan yang berbeda pula. Tingkatan user tersebut dibagi menjadi operator, engineer, dan manajer. Untuk mengetahui lebih lanjut mengenai rancangan tampilan User-Interface,

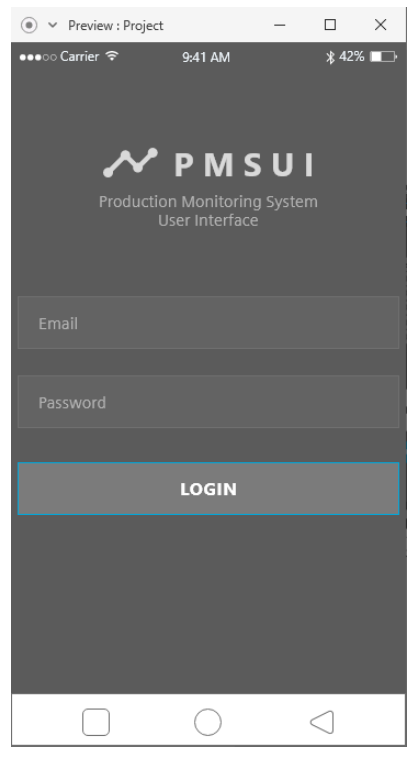

Gbr 4. Screen Login

Pada screen login yang ditunjukkan pada Gambar 4 terdapat dua form input yaitu form email dan password. Setiap user melakukan login dengan email yang berbeda-beda. Setelah proses pengisian form input sudah selesai maka berikutnya user perlu menekan button LOGIN untuk masuk ke halaman dashboard User-Interface. 


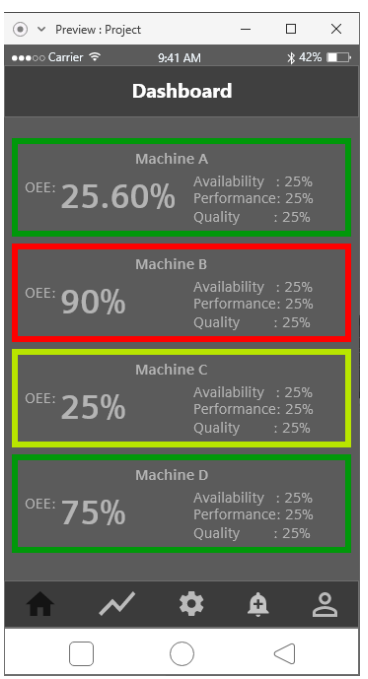

Gbr 5. Screen Dashboard

Pada gambar 5 terdapat tampilan screen dashboard pada tampilan ini terdapat 4 kotak yang merupakan pemisah indicator mesin. Tampilan dashboard ini merupakan screen utama pada User Interface Process Control System. Pada screen ini ditampilkan nilai OEE. Nilai OEE ditampilkan karena OEE merupakan salah satu parameter utama dari sistem monitoring ini terutama untuk monitoring mesin. Selain itu juga terdapat garis kotak yang berbeda warna. Setiap warna menunjukkan status mesin yang sedang berjalan. Warna merah menunjukkan kondisi mesin sedang tidak berjalan. Warna kuning menunjukkan kondisi mesin sedang ada trouble. Dan warna hijau menunjukkan kondisi mesin sedang berjalan. Pemberian warna pada kotak ini ditujukan untuk mempermudah user dalam mengetahui status mesin.

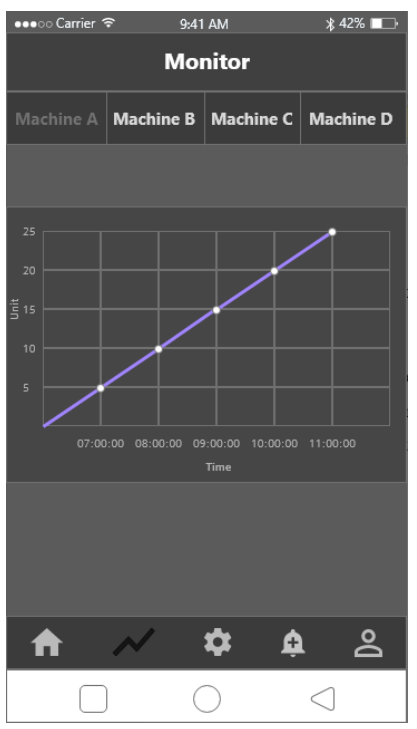

Gbr 6. Screen Monitoring

Screen yang ditunjukkan pada gambar 6 terdapat grafik jumlah produksi. Grafik ini akan melakukan pembaharuan setiap ada penambahan produk. Hal ini mempermudah user untuk memonitoring kondisi produksi yang sedang berlangsung.

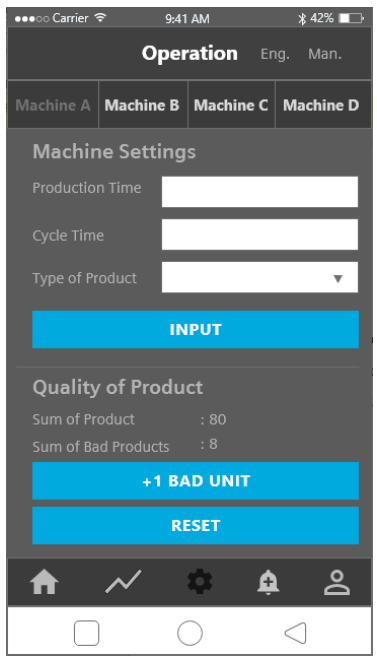

Gbr 7. Screen Operation (Operator)

Pada screen operation (operator) yang ditunjukkan pada Gambar 7 terdapat pengaturanpengaturan dari Process Control System. Pengaturanpengaturan pada screen ini meliputi waktu produksi, tipe produk, cycle time, dan input button untuk produk gagal. Selain itu juga ditampilkan jumlah produk yang sudah diproduksi dan jumlah produk yang gagal. Pengaturan-pengaturan ini diperlukan untuk menunjang parameter-parameter yang nantinya akan dimonitoring. Pada screen ini terdapat perbedaan tampilan dari tiap tingkatan user.

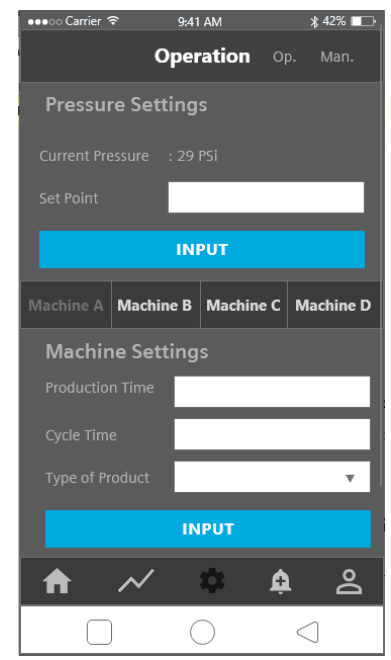

Gbr 8. Screen Operation (Engineer)

Pada gambar 8 terdapat tampilan screen operation (engineer). Screen operation engineer ini memiliki perbedaan dari screen operation (operator) yaitu pada pengaturan nilai tekanan angin. Pengaturan ini disediakan untuk engineer karena cakupan tugas dari engineer ini lebih luas dibandingkan operator yang dapat melakukan tindakan keputusan pengubahan nilai tekanan berdasarkan respon yang ada. 


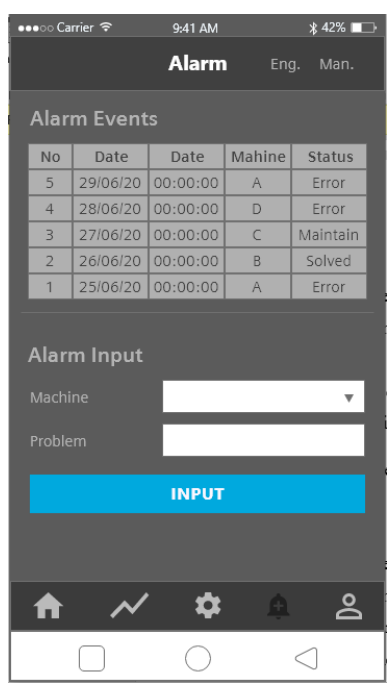

Gbr 9. Screen Alarm (Operator)

Pada screen alarm yang ditunjukkan pada Gambar 9 terdapat trouble list yang merupakan list permasalahan dari mesin. Trouble list ini dimasukkan oleh operator dengan cara memasukkan tipe mesin dan problem yang akan masuk ke database dan memberikan peringatan ke tingkatan engineer.

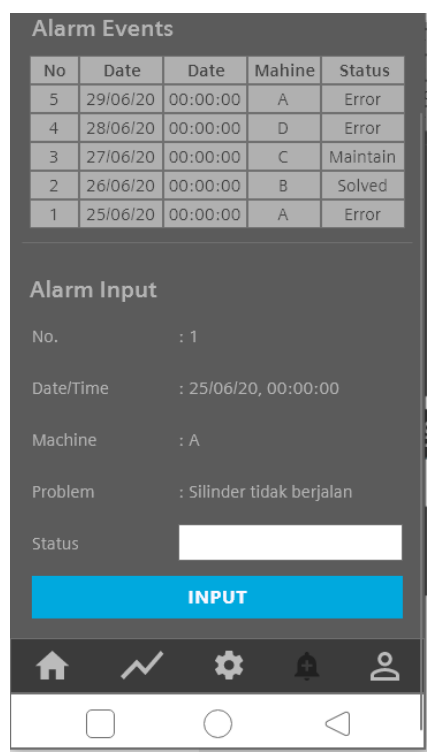

Gbr 10. Screen Alarm (Engineer)

Pada gambar 10 terdapat tampilan screen alarm (engineer). Pada tampilan ini terdapat list trouble dari mesin. Screen alarm (engineer) ini selain berfungsi untuk memonitor permasalahan yang ada pada mesin, screen ini juga berfungsi untuk memberikan status kondisi mesin jika trouble sudah dapat diatasi. Cara untuk memasukkan status kondisi mesin sudah diperbaiki adalah dengan cara menekan list error yang bermasalah.

\section{B. Pengujian Sensor dan Tombol}

Berdasarkan perancangan sistem yang sudah dibuat sebelumnya, terdapat beberapa instrumen yang terdapat pada Process Control System, diantaranya adalah sensor dan tombol. Untuk menguji fungsi dari sensor dan tombol maka dilakukan pengujianpengujian sebagai berikut.

1) Pengujian Limit Switch: Limit switch pada Process Control System ini berfungsi untuk menghitung produksi yang terjadi. Untuk menguji fungsi dari limit switch ini, diukur kecepatan respon pengiriman data dari limit switch ke Arduino dengan menggunakan stopwatch. Berikut adalah hasil pengujian limit switch seperti terlihat pada tabel I dibawah ini.

TABEL I

PENGUJIAN LIMIT SWITCH

\begin{tabular}{|c|c|c|c|c|}
\hline $\begin{array}{c}\text { Penguj } \\
\text { ian ke- }\end{array}$ & $\begin{array}{c}\text { Limit } \\
\text { Switch } \\
\mathbf{1} \text { (ms) }\end{array}$ & $\begin{array}{c}\text { Limit } \\
\text { Switch 2 } \\
\text { (ms) }\end{array}$ & $\begin{array}{c}\text { Limit } \\
\text { Switch 3 } \\
\text { (ms) }\end{array}$ & $\begin{array}{c}\text { Limit } \\
\text { Swich } \\
\mathbf{4} \text { (ms) }\end{array}$ \\
\hline 1 & 19 & 22 & 19 & 25 \\
\hline 2 & 22 & 25 & 25 & 19 \\
\hline 3 & 22 & 22 & 19 & 19 \\
\hline 4 & 22 & 22 & 19 & 19 \\
\hline 5 & 22 & 22 & 19 & 25 \\
\hline 6 & 22 & 22 & 22 & 22 \\
\hline 7 & 19 & 22 & 19 & 19 \\
\hline 8 & 22 & 21 & 19 & 23 \\
\hline 9 & 19 & 19 & 20 & 20 \\
\hline 10 & 22 & 19 & 19 & 23 \\
\hline 11 & 22 & 20 & 23 & 20 \\
\hline 12 & 19 & 20 & 20 & 20 \\
\hline 13 & 19 & 22 & 21 & 19 \\
\hline 14 & 19 & 22 & 19 & 22 \\
\hline 15 & 25 & 25 & 19 & 19 \\
\hline Rata- & & & & \\
\hline rata & $\mathbf{2 1}$ & $\mathbf{2 1 , 6 7}$ & $\mathbf{2 0 , 1 3}$ & $\mathbf{2 0 , 9 3}$ \\
\hline & & & & \\
\hline
\end{tabular}

Untuk mengetahui gambaran data dari table tersebut maka dibuat grafik sebagai berikut. 


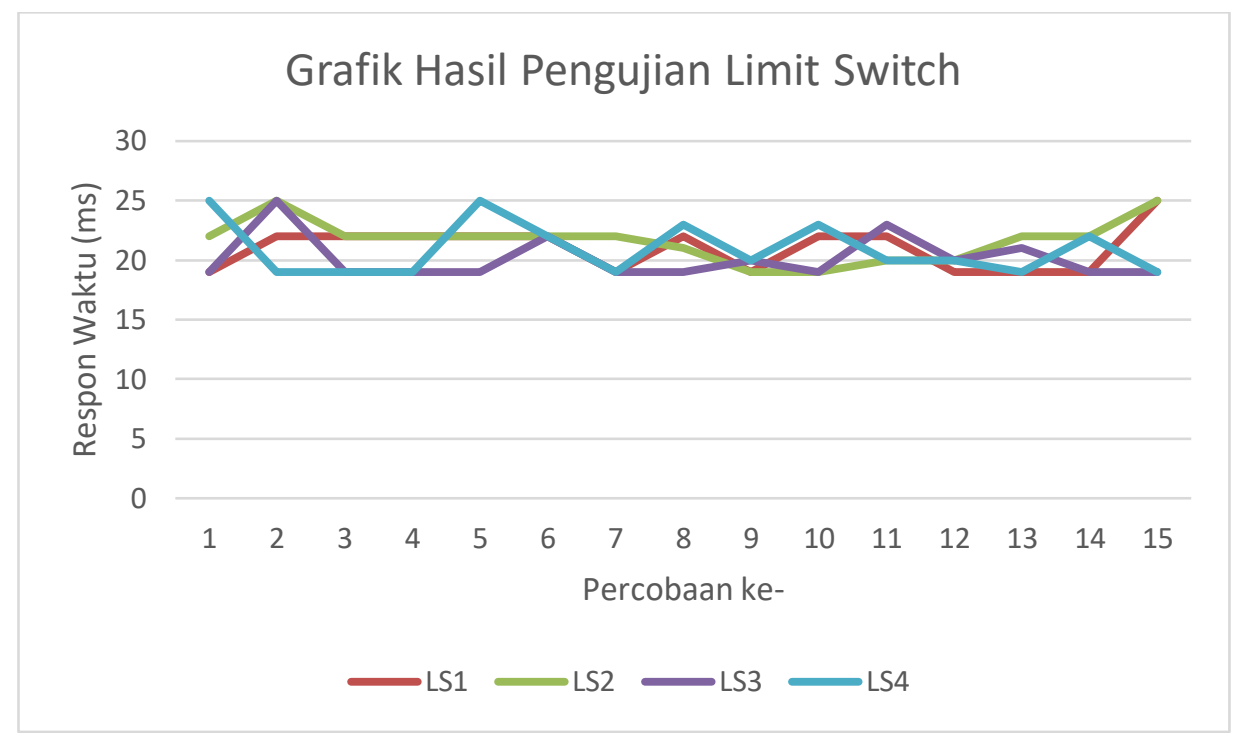

Gbr 11. Grafik Hasil Pengujian Limit Switch

\section{Pengujian Repeatabilitas Sistem}

Repeatability adalah variasi dalam pengukuran yang didapat dari satu alat pengukuran ketika digunakan beberapa kali oleh appraise pada pengukuran suatu karakteristik pada part yang sama [2.

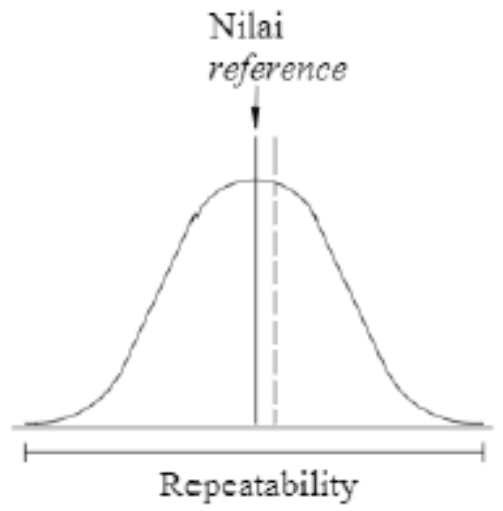

Gbr 11. Repeatability [29]

Pada pengujian ini digunakan untuk menguji sifat keterulangan sistem yang telah dibuat, hal ini bertujuan untuk menunjukkan apakah sistem memiliki sifat repeatability yang baik atau tidak. Pada proses pengujian repeatability sistem dilakukan 3 kali pengujian secara berulang. Tujuan dari pengujian ini yaitu membandingkan perbedaan output pembacaan limit switch dan respon waktu pembacaan pada sistem Android yang dibaca dengan pengujian yang dilakukan secara berulang menggunakan jumlah produksi yang sama.
TABEL II

DATA HASIL PENGUJIAN PRODUKSI PADA MESIN A
\begin{tabular}{|c|c|c|c|c|}
\hline No & $\begin{array}{c}\text { Jumlah } \\
\text { Produksi }\end{array}$ & $\begin{array}{c}\text { Pengu } \\
\text { jian 1 }\end{array}$ & $\begin{array}{c}\text { Peng } \\
\text { ujian } \\
\mathbf{2}\end{array}$ & $\begin{array}{c}\text { Penguj } \\
\text { ian 3 }\end{array}$ \\
\hline $\mathbf{1}$ & 50 & 50 & 50 & 0 \\
\hline $\mathbf{2}$ & 50 & 50 & 50 & 49 \\
\hline $\mathbf{3}$ & 50 & 51 & 50 & 50 \\
\hline $\mathbf{4}$ & 50 & 50 & 51 & 50 \\
\hline $\mathbf{5}$ & 50 & 50 & 50 & 49 \\
\hline
\end{tabular}

TABEL III

DATA PENGUJIAN WAKTU PENGIRIMAN DATA PADA MESIN A

\begin{tabular}{|c|c|c|c|}
\hline No & Pengujian 1 & Pengujian 2 & Pengujian 3 \\
\hline $\mathbf{1}$ & 2.00 & 2.00 & 2.00 \\
\hline $\mathbf{2}$ & 2.02 & 2.02 & 2.02 \\
\hline $\mathbf{3}$ & 2.00 & 2.07 & 2.05 \\
\hline $\mathbf{4}$ & 2.05 & 2.05 & 2.05 \\
\hline $\mathbf{5}$ & 2.04 & 2.04 & 2.06 \\
\hline
\end{tabular}

Dari Pengujian yang diambil pada mesin A didapatkan nilai mendekati sama disetiap proses pengujian dari 3 kali pengujian yang dilakukan. Untuk pengujian jumlah produksi pada gambar 4.21(a) data yang diterima tidak terjadi error yang besar dan sistem memiliki sifat repeatability yang baik. Untuk gambar 4.21(b) merupakan nilai respon waktu yang didapat dari proses pengiriman data mesin A.

Dari pengujian repeatability yang dilakukan dapat disimpulkan bahwa sistem mampu bekerja secara konsisten dalam pembacaan actual produksi pada 
setiap mesin setelah dilakukan pengujian sebanyak 3 kali pengujian dengan data produksi mesin yang sama sebanyak 50 kali proses. Sementara pada proses perhitungan waktu yang terjadi setelah 3 kali proses pengujian didapatkan hasil yang cukup stabil dalam

Page 57 pengiriman waktu pada setiap mesin A, mesin B, mesin $\mathrm{C}$, mesin D. Dalam pengujian ini dibuktikan bahwa sistem PMS berbasis Internet of Thing memiliki sifat repeatability yang bagus setelah 3 kali pengujian system.

\section{IV.PENUTUP}

\section{A. Kesimpulan}

Proses Control System pada mesin stamping Berbasis Internet of Thing adalah sistem kontrol yang efektif dan efisien untuk digunakan pada sebuah industri. Berdasarkan pengujian yang telah dilakukan terhadap sistem kontrol tersebut, dapat ditarik beberapa kesimpulan sebagai berikut :

1. Process Control System berhasil di buat dengan menggunakan perangkat smartphone berbasis Android sebagai interfacenya.

2. Proses Control System lebih user friendly karena dapat di akses kapanpun dan dimanapun dengan menggunakan perangkat smartphone berbasis android.

3. Proses pengiriman data yang cukup realiable dan realtime dengan tingkat akurasi $90 \%$.

4. Perhitungan nilai efisiensi mesin meliputi Availibility, Performance, Quality, dan OEE bekerja secara akurat dan handal dengan akurasi sebesar $0.2 \%$ dan erorr presisi sebesar $1 \%$;

5. Sistem monitoring yang telah dibuat berhasil menjawab dan mengatasi masalah pada penelitian sebelumnya mengenai perhitungan nilai efisiensi mesin, respon waktu yang lebih cepat, user friendly interface, akurasi data yang handal..

\section{B. Saran}

Perlu perbaikan Prototype Mesin stamping agar lebih sesuai dengan kondisi mesin yang sebenarnya, baik dari segi desain, mekanikal maupun sensor-sensor yang ada didalamnya, sehingga proses pengujian lebih reliable karena sesuai dengan kondisi yang ada di Industri. Juga kedepan untuk kontrollernya perlu diganti dengan menggunakan PLC agar system wiring menjadi lebih efektif dan efisien. Serta perlunya perhitungan analisis OEE (efisiensi sistem) yang lebih akurat untuk memastikan bahwa system yang dibuat lebih baik dibandingkan system yang sudah ada.

\section{UCAPAN TERIMA KASIH}

Kami mengucapkan terimakasih yang sebesarbesarnya kepada pihak Polman Bandung yang telah memberikan bantuan berupa fasilitas dan dana penelitian juga rekan dosen yang telah memberikan sumbangsih pemikiran dan tenaganya sehingga penelitian ini dapat selesai tepat waktu.

\section{DAFTAR PUSTAKA}

[1] H. Prasetyo and W. Sutopo, "Industri 4.0: Telaah Klasifikasi Aspek Dan Arah Perkembangan Riset," J@ti Undip J. Tek. Ind., vol. 13, no. 1, p. 17, 2018.

[2] H. Hery, P. Endi, and N. R. U. Niel, "Sistem monitoring proses produksi pada mesin bardi di pt. Tirta investama (Danone aqua) sukabumi berbasis Android," Setrum, vol. 3, no. 1, pp. 26-34, 2014.

[3] Potdar Snehal Dilip \& S. R. Jagtap, "REMOTE MONITORING \& CONTROLLING OF REAL TIME INDUSTRIAL It InPARAMETERS WITH GSM \& ETHERNET\thn," Int. J. Electron. Commun. Instrum. Eng. Res. Dev. , vol. 3, no. 3, pp. 1-10\t, 2013.

[4] P. Cowling and M. Johansson, "Using real time information for effective dynamic scheduling," Eur. J. Oper. Res., vol. 139, no. 2, pp. 230-244, 2002.

[5] A. Snatkin, K. Karjust, and T. Eiskop, "Real time Process Control Systemin SME," Proc. Int. Conf. DAAAM Balt. , no. April, pp. 573-578, 2012.

[6] S. K. Subramaniam, S. H. Husin, and Y. Yusop, "Machine efficiency and man power utilization on production lines," Proc. 8th WSEAS Int. Conf. Electron. HARDWARE, Wirel. Opt. Commun., no. May 2014, pp. 70-75, 2011.

[7] H. Meyer, F. Fuchs, and K. Thiel, Manufacturing Execution Systems optimal design, planning, and deployment. McGraw Hill, New York, 2009

[8] S. Siva Kumar, H. Siti Huzaimah, Y. Yusmarnita, and H. Abdul Hamid, "Real time production performance monitoring system a production aid for all industries," Int. Conf. CIRCUITS, Syst. Electron. SIGNAL Process., no. December, pp. 181-184, 2007.

[9] S. Sukaridhoto, Bermain dengan Internet of Things \& BigData. Surabaya: Politeknik Elektronika Negeri Surabaya, 2016.

[10] A. H. Saptadi, "Sistem Akuisisi Data Multiplatform Berbasis PC dengan Tampilan Hasil di Twitter," J. Rekayasa Elektr., vol. 11 , no. 5 , p. 157,2015 .

[11] J. Desember and T. Andrasto, "Pengembangan Sistem Database Hasil Penelitian Dan Pengabdian Kepada Masyarakat Dosen Unnes," Emit. - J. Tek. Elektro, vol. 5, no. 2, 2013.

[12] A. H. Saptadi, "Perbandingan Akurasi Pengukuran Suhu dan Kelembaban Antara Sensor DHT11 dan DHT22," $J$. INFOTEL - Inform. Telekomun. Elektron., vol. 6, no. 2, p. 49, 2014

[13] M. A. Amarullah and A. Suprianto, "Penggunaan Algorithma AES-RIJNDAEL Pada Sistem Enkripsi Dan Dekripsi Untuk Komunikasi Data," vol. 25, no. 2, pp. 31-39, 2015. 